\title{
Examining the Relations Among Narcissism, Impulsivity, and Self-Defeating Behaviors
}

\author{
Joshua D. Miller, W. Keith Campbell, Diana L. Young, \\ Chad E. Lakey, Dennis E. Reidy, Amos Zeichner, and \\ Adam S. Goodie \\ University of Georgia
}

\begin{abstract}
A recent meta-analysis (S. Vazire \& D. C. Funder, 2006) suggested that narcissism and impulsivity are related and that impulsivity partially accounts for the relation between narcissism and self-defeating behaviors (SDB). This research examines these hypotheses in two studies and tests a competing hypothesis that Extraversion and Agreeableness account for this relation. In Study 1, we examined the relations among narcissism, impulsivity, and aggression. Both narcissism and impulsivity predicted aggression, but impulsivity did not mediate the narcissism-aggression relation. In Study 2, narcissism was related to a measure of SDB and manifested divergent relations with a range of impulsivity traits from three measures. None of the impulsivity models accounted for the narcissism-SDB relation, although there were unique mediating paths for traits related to sensation and fun seeking. The domains of Extraversion and low Agreeableness successfully mediated the entire narcissism-SDB relation. We address the discrepancy between the current and meta-analytic findings.
\end{abstract}

A recent meta-analytic review (Vazire \& Funder, 2006) concluded that narcissism is significantly associated with impulsivity (weighted mean $r=.41$ ). These researchers further proposed that this association may account, in part, for the positive relation between narcissism and self-defeating behavior (SDB). We refer to these two hypothesized relations - (a) There is a significant link between

This research was supported in part by National Institutes of Health research grant MH067827 to A.S.G. Data for Study 2 were collected as part of the Georgia Personality Addiction Affect and Decision-making (G-PAAD) study.

Correspondence concerning this article should be addressed to Joshua D. Miller, Department of Psychology, University of Georgia, Athens, GA 30602-3013. E-mail: jdmiller@uga.edu.

Journal of Personality 77:3, June 2009

(C) 2009, Copyright the Authors

Journal compilation (C) 2009, Wiley Periodicals, Inc.

DOI: $10.1111 / \mathrm{j} .1467-6494.2009 .00564 . \mathrm{X}$ 
narcissism and impulsivity, and (b) impulsivity can help explain the relation between narcissism and SDB-as the narcissism-impulsivity hypothesis. This hypothesis is both interesting and provocative in that it differs from models of narcissism that focus primarily on selfesteem regulation (Morf \& Rhodewalt, 2001; Raskin, Novacek, \& Hogan, 1991) and findings that focus specifically on approachrelated motivation such as behavioral activation or sensation seeking (e.g., Campbell, Brunell, \& Finkel, 2006; Emmons, 1981).

The narcissism-impulsivity hypothesis is also surprising in that most dispositional examinations of narcissism do not identify impulsivity as a core component. For example, a large body of research exists on the relations between the Five-Factor Model (FFM) of personality and narcissism; the majority of these findings suggest that narcissism is most strongly linked with Agreeableness and Extraversion (see Miller \& Campbell, 2008, for a review). Although Whiteside and Lynam (2001) have suggested that there is an impulsivity-related trait on Extraversion (i.e., Excitement Seeking), they note that, within the FFM, the majority of impulsivity-related traits reside in Conscientiousness (i.e., Self-discipline, Deliberation) or Neuroticism (i.e., Impulsiveness), neither of which is a reliable correlate of narcissism.

\section{Exploring the Narcissism-Impulsivity Hypothesis}

The narcissism-impulsivity hypothesis proposes that impulsivity partially explains the link between narcissism and SDBs such as self-enhancement and aggression, as well as other behaviors that lead to negative long-term outcomes. More specifically, "a dispositional perspective suggests that narcissists react aggressively to an insult because they are impulsive; there is no internal subjective logic to their behavior, they are simply overcome by impulses that they fail to contain" (Vazire \& Funder, 2006, p. 158). This variant of a dispositional model is different from cognitive-affective processing models, which hold that although narcissistic individuals' "behavior seems self-defeating to the outside observer, it is actually a deliberate, though ill-conceived, strategy that makes sense from the point of view of their internal subjective logic" (Vazire \& Funder, 2006, p. 155). This new model is also different from other trait models of narcissism. Ultimately, the narcissism-impulsivity hypothesis argues for the existence of this type of relation on the basis of the obser- 
vation that impulsivity and narcissism both demonstrate similar patterns of relations with external correlates such as aggression and negative long-term outcomes. Thus, with regard to aggression, "knowing that narcissists are impulsive, that impulsivity is linked to aggression, and that impulsivity is a biologically-based temperament that exerts strong influences on behavior, it is reasonable to suppose that narcissists' aggression is due in part to their impulsive temperament" (Vazire \& Funder, 2006, p. 160).

In the current study we theoretically and empirically review these two points. First, is narcissism related to impulsivity? (Before addressing this question we discuss the important and unresolved question of what impulsivity actually represents.) Second, if narcissism is related to impulsivity, an empirical test must establish whether impulsivity explains the relation between narcissism and SDB.

\section{Conceptualizations of Impulsivity}

Using an inclusive approach common in meta-analyses (i.e., including a large array of traits such as impulsivity, self-control, ego control, constraint, ability to delay gratification, deliberation), Vazire and Funder's (2006) study operationalized impulsivity as a unitary construct. Although this is understandable given the need for an adequate number of effects in order to conduct a meta-analysis, there are difficulties inherent in this strategy. There is considerable evidence in the personality literature that the general term "impulsivity" reflects a cluster of diverse constructs that are related primarily because they lead to similarly maladaptive outcomes (Whiteside \& Lynam, 2001; Whiteside, Lynam, Miller, \& Reynolds, 2005). In fact, there is some evidence to suggest that impulsivityrelated traits may differ substantially in their underlying etiology (see Depue \& Collins, 1999, for a review) with some traits reflecting dopaminergic functioning (e.g., traits related to novelty/sensation/ reward seeking and the broader domain of Extraversion; Wacker, Chavanon, \& Stemmler, 2006) and others related to serotonergic functioning (e.g., traits related to acting without forethought and the broader domain of Conscientiousness; Manuck et al., 1998). Given this consideration, it is possible that narcissism is differentially related to specific impulsivity-linked traits. We review three alternative conceptualizations of impulsivity or related traits that may be in- 
corporated under the umbrella of impulsivity (Whiteside \& Lynam, 2001).

\section{UPPS-P Model}

Comprehensive models of personality such as the FFM (Costa \& McCrae, 1992) and Tellegen's (1985) three-factor model invariably include personality traits related to impulsivity. Whiteside and Lynam (2001), however, noted the inconsistency of the trait definitions and locations (i.e., within larger personality domains) of impulsivity-related traits and addressed this by using a comprehensive model of personality, Costa and McCrae's specific variant of the FFM, as a starting point. They argued that four impulsivity-related traits are present across three different domains: Neuroticism (i.e., "Impulsiveness" facet), Extraversion (i.e., "Excitement Seeking" facet), and Conscientiousness (i.e., "Self-discipline" and "Deliberation" facets). These authors factor analyzed items from 20 prominent impulsivity scales, including these 4 trait scales from Costa and McCrae's Revised NEO Personality Inventory (NEO PI-R), as well as scales from other prominent models of personality or impulsivity such as Tellegen's Control subscale, Barratt's Impulsiveness subscales, and Cloninger's Impulsivity scale. The result of this process was four scales that are consistent with the four hypothesized markers from the FFM (i.e., UPPS: Urgency, (lack of) Premeditation, (lack of) Perseverance, Sensation Seeking). The UPPS thus represents a broad measure of impulsivity, as it includes traits from three of the five major domains of the FFM.

Consistent with the notion that some "impulsive" behavior is driven by negative affectivity, they termed one factor "Negative Urgency" (i.e., an individual's difficulty in resisting cravings and urges when in a negative affective state). Factors 2 and 3 are consistent with an understanding of impulsivity from the perspective of Conscientiousness: "(Lack of) Perseverance" (i.e., a tendency to give up easily because of boredom, fatigue, or task difficulty) and "(Lack of) Premeditation" (i.e., a tendency to fail to pause and deliberate before acting). The fourth factor is consistent with an understanding of impulsivity from the perspective of Extraversion: "Sensation Seeking" (i.e., an interest in and tendency to pursue activities that may be exciting, novel, or involve some degree of risk). Lynam, Smith, Whiteside, and Cyders (2006) recently included a fifth scale entitled 
Positive Urgency (i.e., difficulty in resisting cravings and urges when in a positive affective state), developed by Cyders, Smith, Spillane, Fischer, and Annus (2007). These five scales (collectively called the UPPS-P; Lynam et al., 2006) provide relatively comprehensive coverage of traits that are often referred to as "impulsivity" in psychological research. Several studies have demonstrated that these scales manifest unique and often divergent relations with relevant constructs such as gambling, substance use, eating and personality disorder symptomatology, and antisocial behavior (e.g., Anestis, Selby, \& Joiner, 2007; Whiteside et al., 2005).

\section{Behavioral Inhibition System/Behavioral Activation System}

Carver and White (1994) developed scales assessing Gray's (e.g., Gray, 1972) constructs of the Behavioral Inhibition System (BIS) and Behavioral Activation System (BAS). Low BIS may be associated with the engagement of externalizing behaviors due to a failure to attend to environmental cues signaling punishment or nonreward. Carver and White suggest that the BIS "inhibits behavior that may lead to negative or painful outcomes" (p. 319). From an FFM perspective, the BIS scale does not seem to be a strong marker of impulsivity, as it is primarily positively related to Neuroticism, with weaker but significant correlations with Agreeableness and Conscientiousness as well (Smits \& Boeck, 2006).

Alternatively, the "BAS responds to environmental cues for reward and nonpunishment by initiating approach and active avoidance" (Whiteside \& Lynam, 2001, p. 672). Although the BAS scales are correlated with impulsivity scales (e.g., Smillie, Jackson, \& Dalgleish, 2006), it has been argued that the BAS is better conceptualized as Extraversion (Smillie, Pickering, \& Jackson, 2006). A recent confirmatory factor analysis found that BAS and "impulsivity" are best modeled as related but distinct constructs (Quilty \& Oakman, 2004). Smits and Boeck (2006) examined the relations between a measure of BIS/BAS and the FFM and found that the BAS scales (Reward Responsiveness, Drive, Fun Seeking) were consistently positively related to Extraversion in two samples ( $r$ s ranged from .16 to .69). Alternatively, the BAS scales demonstrated inconsistent relations with Conscientiousness such that Reward Responsiveness was nonsignificantly correlated $(r \mathrm{~s}=.04$ and .16$)$, Drive was either nonsignificantly related or positively correlated $(r \mathrm{~s}=.02$ and .21$)$, and Fun 
Seeking was negatively related $(r \mathrm{~s}=-.25$ and -.28$)$. None of the BAS scales evinced relations with Conscientiousness that would be considered greater than a "small" effect size. BAS also appears to be associated with dopaminergic functioning (Depue \& Collins, 1999). Many studies have been conducted using the BIS/BAS scales, which have demonstrated significant and divergent relations with constructs such as disordered eating (Loxton \& Dawe, 2001) and substance use (Johnson, Turner, \& Iwata, 2003).

\section{Self-Control}

Self researchers who focus on the overarching ability to control one's own behavior have developed an assessment of trait self-control (Tangney, Baumeister, \& Boone, 2004). Their approach focuses on broad-spectrum failure of self-control (e.g., resisting temptation, bad habits, emotion control, and healthy diet) and has traditionally been linked to a "muscle-like" model of self-control. In this "muscle model," it is argued that self-control would diminish with use in the short-term but strengthen with use in the long-term (e.g., Muraven \& Baumeister, 2000). Tangney et al. developed a measure of this trait called the Brief Self-Control scale (BSCS), which demonstrated significant correlations with symptoms of eating disorders, alcohol abuse, and antisocial and borderline personality disorders. Of the Big Five traits, the BSCS evinced the largest correlation (i.e., $r=.48$, $p<.01)$ with Conscientiousness.

\section{Exploring the Narcissism-Impulsivity Hypothesis: Issue 1: How Is Impulsivity in This Model Conceptualized?}

Proponents of the narcissism-impulsivity hypothesis appear to focus primarily on traits in which the impulsive behavior is putatively due to a lack of forethought and internal constraint, not approach tendencies. Thus, the operationalization of impulsivity in this model appears to be more relevant to the Conscientiousness-related domain of personality, but the model is not precise regarding the conceptualization of impulsivity it espouses, and it is possible that it could be broader than the operationalization. Many of the traits included by Vazire and Funder (2006) in their meta-analysis appear to fall under the rubric of Conscientiousness or Constraint. For example, Vazire and Funder did not include in their search and subsequent metaanalysis traits such as sensation, excitement, or novelty seeking or 
approach orientation (e.g., Behavioral Activation scales) despite empirical evidence (e.g., Emmons, 1981; Foster \& Trimm, 2008) that narcissism is associated with impulsivity-related traits like these. Instead, their search focused on the following terms: impulsivity, impulsiveness, impulse control, self-control, ego control, constraint, ability to delay gratification, and patience or impatience. It is also unclear what some of the impulsivity traits included measure (e.g., ego undercontrol) or how they would be categorized with regard to the various types of impulsivity discussed earlier. For example, Letzring, Block, and Funder (2005) found that ego undercontrol was multidimensional in nature, as it was significantly correlated with Conscientiousness $(r=-.27)$, Agreeableness $(r=-.29)$, Extraversion $(r=.34)$, Neuroticism $(r=.27)$, and Openness $(r=.32)$. Thus, some of Vazire and Funder's impulsivity measures tapped a variety of personality constructs, which makes it difficult to conceptualize how they are related to narcissism.

Overall, Vazire and Funder (2006) reported a relatively large mean effect size for the relation between narcissism and impulsivity. This is surprising, as narcissism has not typically been associated with impulsivity, at least as it is conceptualized in the domains of Conscientiousness or Constraint. For example, a meta-analytic review by Saulsman and Page (2004) found an effect size (i.e., $r$ ) of .06 between narcissistic personality disorder (NPD) and Conscientiousness; likewise, most studies that have examined the relations between the NPI and the Big Five/FFM have not found a significant negative correlation with Conscientiousness (e.g., Miller \& Campbell, 2008; Paulhus \& Williams, 2002; Samuel \& Widiger, 2008). Vazire and Funder's findings would likely have been less surprising if the metaanalytic results included traits related to Extraversion-based traits such as sensation seeking, excitement seeking, or behavioral activation, as Extraversion appears to be a primary component of narcissism.

Given these findings, how can this substantial mean effect size be explained? We argue that a partial explanation may lie in the fact that several of the impulsivity measures used in this meta-analysis show signs of substantial predictor-criterion overlap with narcissism. Ten of the 23 effect sizes reported in the meta-analysis use measures of impulsivity that are questionable on these grounds. As one example, 5 of the 23 effect sizes $(22 \%)$ used the Self-Control (Sc) scale of the California Personality Inventory (CPI; Gough, 1969) to 
operationalize impulsivity, even though the Sc scale was designed to measure "the degree and adequacy of self-regulation and self-control and freedom from impulsivity and self-centeredness" (Gough, 1969, p. 10; italics added). Included in this measure are items such as: A person needs to "show off" a little now and then; I like to be the center of attention; I must admit that I often try to get my own way regardless of what others may want; I am apt to show off in some way if I get the chance; and I like to boast about my achievements every now and then. These items are more pertinent to self-enhancement, a central feature of narcissism, than to impulsivity. Similar problems can be found for other measures included in their metaanalysis, including ACL self-control scale, Block's ego-undercontrol scale and CAQ ego-undercontrol scale. ${ }^{1}$ We believe that one would obtain a more accurate picture of the relation between narcissism and impulsivity with the use of nonoverlapping measures.

\section{Exploring the Narcissism-Impulsivity Hypothesis: Issue 2: Is There Evidence for a Mediating Role of Impulsivity?}

Even to the extent that data support a link between narcissism and impulsivity, there are simply no data available to support the second hypothesis, that impulsivity mediates the narcissism-SDB relation. For example, although it is possible that impulsivity is linked to $\mathrm{SDB}$, it may not explain why narcissistic individuals engage in behaviors such as aggression. Narcissism is consistently linked with other traits such as low Agreeableness (i.e., Miller \& Campbell, 2008; Paulhus \& Williams, 2002) that are known correlates of aggression

1. One of the largest effect sizes in the meta-analysis used the ACL self-control scale (reversed; r), which also includes items that appear to be more strongly linked with narcissism than with impulsivity: mild (r), quiet (r), self-denying (r), withdrawn (r), forceful, headstrong, loud, opinionated, and outspoken. Four of the effect sizes used measures designed to capture Block and Block's (1980) construct of ego undercontrol. Self-report items from the Ego undercontrol scale (Block \& Kremen, 1996) include the following: I like to flirt; In a group of people I would not be embarrassed to be called on to start a discussion or give an opinion on something I know well; I would like to wear expensive clothes; I am easily downed in an argument (r); and I have often had to take orders from someone who did not know as much as I did. Finally, some of the most prototypical items from the CAQ Ego undercontrol prototype (Funder \& Block, 1989) include behaves in an assertive fashion; self-dramatizing/histrionic; guileful and deceitful, manipulative, opportunistic; genuinely submissive; accepts domination comfortably. 
and other externalizing behaviors (e.g., Krueger, Markon, Patrick, Benning, \& Kramer, 2007) that may also account for the relation between narcissism and SDB.

One could examine this postulate by testing whether the relation between narcissism and self-defeating behavior is mediated by impulsivity-related traits. By this we do not suggest testing whether narcissism leads to impulsivity which, in turn, leads to self-defeating behaviors, but rather, testing whether impulsivity, as part of narcissism, accounts for the relation between narcissism and SDB. This type of analysis would provide an empirical test of this proposition.

\section{An Alternative Hypothesis: Extraversion and Agreeableness as Mediators of the Narcissism-SDB Relation}

We believe that a more powerful and specific trait model exists for understanding why narcissism is linked to SDB, and it is predicated on two lines of evidence. First, as noted above, there are other personality traits that are more central to narcissism than impulsivity (i.e., Extraversion and low Agreeableness). Second, we believe that these other narcissism-related traits, particularly Agreeableness, may be better predictors of many of the behaviors deemed "self-defeating" and are also linked to negative outcomes. We must note that this high extraversion/agency and low agreeableness/communion model of narcissism is not new. It is central to several models for understanding narcissism, including Paulhus's (2001) Minimalist Model, Campbell and colleagues' Agency Model (e.g., Campbell et al., 2006), and models of PDs based on the interpersonal circumplex (e.g., Wiggins \& Pincus, 2002).

The data suggest that a trait description of narcissism is best accounted for not by impulsivity but by high levels of Extraversion (particularly agentic aspects such as assertiveness, activity level, and excitement seeking) and low levels of Agreeableness (e.g., Jakobwitz \& Egan, 2006; Miller \& Campbell, 2008; Paulhus \& Williams, 2002). In fact, a recent study of narcissism and personality found that although the FFM domains of Extraversion and Agreeableness were significantly related to narcissism across two samples, only one of the four impulsivity-related traits thought to exist in a measure of the FFM (i.e., NEO PI-R) was significantly related to narcissism, specifically the Excitement Seeking facet of Extraversion (Miller \& Campbell, 2008). Similarly, Samuel and Widiger (2008) 
examined the relations between five measures of narcissism and the NEO PI-R and found that only the facet of Excitement Seeking (of the four impulsivity-related traits specified by Whiteside \& Lynam, 2001) was consistently related to narcissism scores. The other three impulsivity-related facets were entirely unrelated to narcissism (i.e., none of the 15 correlations were significant).

Agreeableness and Extraversion are not only more strongly and consistently linked to narcissism, but Agreeableness is also a strong predictor of some of the behaviors labeled self-defeating by Vazire and Funder (2006). For instance, Agreeableness is typically among the strongest personality predictors that emerge in meta-analytic reviews of negative outcomes such as antisocial behavior (Miller \& Lynam, 2001) and risky sexual behavior (Hoyle, Fejfar, \& Miller, 2000). Agreeableness is also a significant predictor of outcomes such as substance use (Flory, Lynam, Milich, Leukefeld, \& Clayton, 2002) and aggression (Bettencourt, Talley, Benjamin, \& Valentine, 2006).

Graziano and Eisenberg (1997) have suggested that Agreeableness measures the degree to which individuals are motivated to work at developing and maintaining prosocial relationships with others. This interpersonally based motivation can be thought of as a "constraint" in that agreeable individuals want to maintain positive interpersonal relations with others and, as a result, are less likely to engage in behaviors that might strain these relationships (e.g., aggression, selfenhancement, grandiose self-presentations). If this constraint is not present, self-defeating behaviors like aggression are more likely (e.g., Konrath, Bushman, \& Campbell, 2006).

Narcissistic individuals show patterns of motivation and behavior that are consistent with low interpersonal constraint. For example, they have high levels of need for power and low levels of need for intimacy (Carroll, 1987), tend to value status more than emotional closeness in interpersonal relations (e.g., Campbell, 1999), and may be more likely to view interpersonal interactions in a zero-sum manner (e.g., Campbell, Bush, Brunell, \& Shelton, 2005). The negative relation between narcissism and Agreeableness, particularly facets suggestive of a disinterest or lack of concern for the welfare of others (i.e., Altruism, Tendermindedness; see Miller \& Campbell, 2008), suggests that these "negative outcomes" (e.g., relationship difficulties; being viewed as arrogant or emotionally detached) may be of little concern to these individuals; instead they may view others as opportunities for self-gratification via self-enhancement, displays of 
dominance, or exploitation. In addition, the positive relation between narcissism and Extraversion (e.g., Paulhus \& Williams, 2002), particularly facets such as "Assertiveness," "Activity," and "Excitement Seeking," suggests that narcissism is generally related to an approach orientation in which individuals are (a) particularly sensitive to reward and excitement and (b) insensitive to signs of punishment or nonreward. As such, narcissistic individuals may engage in self-defeating behaviors such as gambling because they become myopically focused on the rewards of such behavior (Lakey, Rose, Campbell, \& Goodie, 2008). Extraversion and related traits such as sensation seeking are also linked to rapid habituation of the startle response, which may predispose these individuals toward engaging in "impulsive" behaviors that are immediately gratifying but carry long-term risk (LaRowe, Patrick, Curtin, \& Kline, 2006).

\section{The Present Research: Reassessing the Magnitude of the Relation Between Narcissism and Impulsivity and Testing Competing Meditational Models}

Because the predictions of the narcissism-impulsivity hypothesis are specific and testable, the goal of the current study was to examine these assertions empirically. In Study 1, we examine whether narcissism is (a) associated with a popular measure of impulsivity and (b) whether impulsivity explains the link between narcissism and a behavioral measure of aggression. The measure of impulsivity used is among the most commonly used in research on personality - the Barratt Impulsiveness Scale-11 (BIS-11; Patton, Stanford, \& Barratt, 1995), which is comprised of three subscales (i.e., Motor, Attention, and Nonplanning Impulsiveness). Factor analytic results from Whiteside and Lynam (2001) suggest that these subscales are most similar to the (Lack of) Premeditation variable from the UPPS$\mathrm{P}$ assessment. We then test whether these impulsiveness scales account for the relation between narcissism and aggression.

In Study 2, we broaden the scope of our study by including multiple conceptualizations of impulsivity in order to characterize the nature of the relations between narcissism and impulsivity with greater specificity. This enables us to examine the narcissism-impulsivity relation in a more specific, narrow manner so as to be able to tease apart the nature of these relations. Importantly, we use models of impulsivity that do not suffer from predictor-criterion 
overlap. We also include other individual difference variables such as Extraversion and Agreeableness, which we believe are central to the description of narcissism and may better account for the relation between narcissism and SDB such as aggression. Additionally, we test whether the inclusion of Conscientiousness, a domain of personality often associated with impulsivity-related traits, improves the mediation model. We also use a broader outcome measure of SDB in Study 2, which incorporates a variety of behaviors that might be considered self-defeating such as risky sex, overspending, and substance use. Overall, the design of this study allows us to test both aspects of the narcissism-impulsivity hypothesis in a comprehensive manner that may help clarify the nature of this relation.

Across the studies we test empirically whether impulsivity explains the link between narcissism and SDB such as aggression. We hypothesize that the impulsivity measures will not be uniformly or strongly related to narcissism. We expect that the impulsivity-related traits that are most strongly linked to Extraversion such as UPPS-P Sensation Seeking and the BAS scales will be positively related to narcissism, whereas impulsivity scales related more strongly to emotion dysregulation (Behavioral Inhibition scale; Positive and Negative Urgency) or Conscientiousness (BIS-11 Impulsiveness scales, Lack of Perseverance, Lack of Premeditation) will be negatively or nonsignificantly related to narcissism. In addition, we anticipate that these measures will not provide substantial mediation of the narcissism-SDB link. Rather, we believe that other personality traits - namely Extraversion and Agreeableness - will better account for this relation.

\section{STUDY 1}

Method

\section{Participants}

Ninety-one undergraduate men (mean age $=19.67, S D=1.26 ; 86 \%$ White) participated in this study for research credit. Only male participants were used, as female participants demonstrate a more restricted range of aggressive responding (e.g., lower intensity, duration, and frequency) in this paradigm (Zeichner, Parrott, \& Frey, 2003). Five participants were excluded because they did not believe that they were administering shocks or were missing data. Thus, 86 participants were used in the present analyses. 


\section{Materials}

Narcissistic Personality Inventory (NPI; Raskin \& Terry, 1988). Narcissism was measured using the 40-item forced choice version of the NPI $(M=17.85, S D=7.6, \alpha=.86)$. This measure is frequently used in the study of narcissism, particularly in the field of social-personality psychology, and has been validated using a wide array of criteria (for a review, see Morf \& Rhodewalt, 2001).

Barratt Impulsiveness Scale-11 (BIS-11; Patton et al., 1995). The BIS11 is a 30 -item self-report measure of impulsiveness that yields three subscales as well as a total score. Items are endorsed on a 1 to 4 scale. The three subscales are Motor Impulsiveness (e.g., "I do things without thinking"; 11 items; $\alpha=.52$ ), Attentional Impulsiveness (e.g., "I concentrate easily"; 8 items; $\alpha=.66$ ), and Nonplanning Impulsiveness (e.g., "I plan tasks carefully"; 11 items; $\alpha=.66$ ).

Response Choice Aggression Paradigm (RCAP; Zeichner, Frey, Parrott, \& Butryn, 1999). Under the guise of a 24-trial reaction time competition, participants used an aggression apparatus consisting of a white metal box mounted with an assortment of electrical switches and light-emitting diodes (LEDs). Ten push-button switches labeled 1 through 10 were provided for the ostensible administration of shocks by the participant to his opponent. A reaction time key was located at the center of the console. Shocks were administered via two electrodes attached to two fingers on the participant's nondominant hand. The experiment was controlled by a three-unit peripheral system interfaced with a PC located in a control room separate from the participant chamber.

We combined the following three aggression scores to create an aggression composite: (1) Shock Intensity is the average intensity of shocks for trials in which the participant administers a shock, (2) Shock Duration is the average duration of shocks for trials during which the participant administers a shock, and (3) Shock Frequency is the number of trials during which the participant chooses to administer a shock. These indices were combined because they were significantly interrelated and we believed that this would create the most reliable $(\alpha=.80)$, global measure of laboratory aggression.

\section{Procedure}

Following provision of informed consent and completion of questionnaires, participants were told that they would be competing in a reaction time task against a male opponent who was in the adjacent chamber. 
They were also told that they would have the opportunity to punish him following each trial through the administration of an electric shock and that their opponent could do likewise (i.e., each participant received 12 shocks from their opponent during the course of the 24 trials). Following each trial, an LED located on a console in front of the participants informed them whether they won or lost and they were then given an opportunity to administer a shock to their opponent, regardless of the trial outcome. This procedure was followed to mimic real-world aggression in which aggression is not necessarily contingent on outcome. To provide participants with a true nonaggression option, they were informed that they were permitted to refrain entirely from administering shocks. To administer a shock, participants pressed 1 of 10 buttons that, ostensibly, incrementally increased the shock intensity from $55 \%$ to $100 \%$ of the opponent's predetermined pain tolerance level. Subjective pain tolerance was determined via administration of shocks in an incremental fashion from the lowest available shock setting, which is imperceptible, until the shocks reached a reported maximum level of tolerable pain. Participants were instructed that their opponent would have access to the identical range of shock levels. LEDs provided feedback as to the level of shock participants received from the opponent.

\section{Results and Discussion}

\section{Relations Between Narcissism, Impulsivity, and Aggression}

Narcissism was significantly related to Attentional Impulsiveness $(r=.22, p<.05)$ but nonsignificantly related to the Motor and Nonplanning Impulsiveness scores, $r \mathrm{~s}=.18$ and -.01 , respectively. Both Attentional and Motor Impulsiveness were related to the aggression composite, $r \mathrm{~s}=.34$ and $.24, p s<.05$, whereas the relation between Nonplanning Impulsiveness and aggression was not significant, $r=.16$. Finally, narcissism was significantly related to the aggression composite, $r=.40, p<.01 .^{2}$

\section{Do Motor, Attention, and Nonplanning Impulsiveness Account for the} Narcissism-SDB Relation?

In this analysis, we tested whether the relations between narcissism and aggression are mediated by the impulsiveness scales (included

2. These data were previously used to report on the relations between the subscales (only) of the NPI and aggression (Reidy, Zeichner, Foster, \& Martinez, 2008). 
simultaneously). To test multiple mediator models in a manner that results in significance tests for the direct effect of $x$ on $y$ controlling for several mediators, as well as the specific indirect effects of various mediators, we utilized Preacher and Hayes's (2006) bootstrapping technique for multiple mediator models. This method allows for multiple mediators to be examined within the same model, has greater power to detect significant effects while allowing for the control of covariates, and does not impose questionable distributional assumptions on the data (e.g., Preacher \& Hayes, 2004). To reveal the precise nature of the mediation, Preacher and Hayes's technique produces point estimates and bias-corrected and accelerated (BCA) confidence intervals for each of the proposed indirect effects, as well as a point estimate of the remaining direct effect. For the indirect effects tests, confidence intervals that do not include zero suggest significant mediation. ${ }^{3}$

We tested whether the three impulsiveness subscales mediated the relation between narcissism and aggression (see Figure 1a). The total effect of narcissism on aggressive behavior was significant $(\mathrm{B}=.13$, $p<.01)$ and remained so once the three mediators were included in the model $(\mathrm{B}=.11, p<.01)$. The total indirect effect of narcissism on aggression through the mediating variables was not significant, with a point estimate of .02 and a $95 \%$ BCA confidence interval of -.001 to .05; there were no significant unique paths through the BIS- 11 impulsiveness subscales.

To summarize, in Study 1 we conducted a preliminary test of both components of the narcissism-impulsivity hypothesis. We found that (a) narcissism manifested weak to nonsignficant correlations with three impulsivity scales, and (b) these impulsivity scales did not mediate the significant relation between narcissism and aggressive behavior. A limitation of this study, however, is that only a narrow form of impulsivity was measured (i.e., primarily related to a lack of forethought), and it is possible that other impulsivity-related traits might prove to be more strongly linked to narcissism and account for the relation between narcissism and SDB. We also used a specific, narrow behavior as our measure of SDB, which may have attenuated

3. We tested all models (i.e., Studies 1 and 2) for problems related to multicollinearity. Cohen, Cohen, West, and Aiken (2003) report that a variance inflation factor (VIF) "of 10 or more provides evidence of serious multicollinearity" (p. 423). The VIFs never exceeded 2.25 in any of the current regression models. 




Figure 1

Test of a mediation model: NPI narcissism and aggression mediated through BIS-11 Impulsiveness scales (Study 1). Path values represent unstandardized regression coefficients. Standard errors are noted in parentheses. Values before the slash represent the direct effect of narcissism on the self-defeating behavior composite (SDBC) after the inclusion of the mediating variables. Values after the slash represent the effect on narcissism on IBC prior to the inclusion of the mediators. $* p<.05, * * p<.01$.

our findings. To address these limitations, in Study 2 we tested multiple models of impulsivity as well as a broader measure of SDB.

\section{STUDY 2}

The results from Study 1 suggest that the relations between narcissism and measures of impulsivity may be substantially smaller than that reported in the Vazire and Funder (2006) meta-analysis, at least with the targeted conceptualization and assessment we used to measure impulsivity in this study. In addition, we did not find evidence to support the hypothesis that impulsivity explained why narcissistic individuals engaged in aggression. Rather, we found that both narcissism and impulsivity were significant, unique predictors of aggressive behavior.

In Study 2, we broaden our assessment of impulsivity and examine several different models including a measure of self-control (BSCS), a measure of approach/avoidance tendencies (i.e., BIS/ BAS), and a measure of impulsivity that was designed to take into account a variety of the conceptualizations often included in descriptions of impulsivity (i.e., UPPS-P). We also include a broader assessment of SDB, namely an index that includes behaviors such as risky sex, substance use, reckless driving, overspending, and eating binges. Finally, we test an alternative mediation model in which we 
hypothesize that the personality domains of Extraversion and Agreeableness may better account for the relation between narcissism and SDB.

\section{Method}

\section{Participants and Procedure}

Participants were 200 students (120 women and 80 men); 163 participants were White (82\%), 17 (9\%) were Black, 14 (7\%) Asian, and the rest reported a multiracial background. Mean age was $19.11(S D=1.36)$. Participants received research credit for their participation.

\section{Materials}

Narcissistic Personality Inventory (Raskin \& Terry, 1988). Narcissism was measured using the 40 -item forced choice version $(M=16.60$, $S D=7.30, \alpha=.84)$.

Impulsivity-related personality traits. The BIS/BAS scales (Carver \& White, 1994) are assessed via 20 self-report questions designed to assess the behavioral inhibition system (BIS) and behavioral activation system (BAS) based on Gray's work (e.g., 1972). The BIS is assessed via seven items (e.g., "I feel worried when I think I have done poorly at something"). The BAS is measured using three short subscales including Reward Responsiveness (five items; e.g., "When I get something I want, I feel excited and energized"), Drive (four items; e.g., "I go out of my way to get things I want"), and Fun Seeking (four items; e.g., "I'm always willing to try something new if I think it will be fun"). In the current study, alphas ranged from .80 (BAS-Fun Seeking) to .92 (BAS-Drive).

UPPS-P Impulsive Behavior Scale (UPPS-P; Lynam et al., 2006). This is a 59-item self-report measure of five traits believed to fall under the umbrella of impulsivity. The Negative and Positive Urgency scales assess an individual's difficulty in resisting cravings and urges when in a negative (e.g., "When I feel bad, I will often do things I later regret in order to make myself feel better now") or positive (e.g., "When I am very happy, I can't seem to stop myself from doing things that can have bad consequences") affective state. (Lack of) Perseverance measures an individual's tendency to give up easily because of boredom, fatigue, or task difficulty (e.g., "I tend to give up easily"). (Lack of) Premeditation assesses an individual's tendency to fail to pause and deliberate before acting (e.g., "My thinking is usually careful and purposeful" [reverse scored]). Finally, 
Sensation seeking measures an individual's tendency to pursue activities that may be exciting, novel, or involves risk (e.g., "I generally seek new and exciting experiences and sensations"). In the current study, alphas ranged from .83 (UPPS-P Sensation Seeking) to .93 (UPPS-P Positive Urgency).

Brief Self-Control Scale (Tangney et al., 2004). This scale is a 13-item self-report measure of "the ability to override or change one's inner responses, as well to interrupt undesired behavioral tendencies (such as impulses) and refrain from acting on them" (Tangney et al., 2004, p. 274). Items include the following: "I am good at resisting temptation" and "Sometimes I can't stop myself from doing something, even if I know it's wrong." In the current study, the alpha for this scale was .86 .

Personality. The NEO PI- $R$ (Costa \& McCrae, 1992) is a 240 -item selfreport measure of the FFM, which includes five broad domains of Neuroticism $(\mathrm{N})$, Extraversion (E), Openness $(\mathrm{O})$, Agreeableness (A), and Conscientiousness $(\mathrm{C})$. In the current sample, we use only the domains of $\mathrm{E}(\alpha=.92), \mathrm{A}(\alpha=.89)$, and $\mathrm{C}(\alpha=.92)$.

Self-defeating behaviors. To assess participation in behaviors that could be termed "self-defeating," we created a composite score using six items from the PDQ-4+borderline PD scale. The PDQ-4+(Hyler, 1994) is a 99item self-report measure of $D S M-I V$ PDs on which items are answered using a yes/no response format. For this composite, individuals were asked if they have "done things on impulse that could have gotten me in trouble" as it pertains to the following six behaviors: "A) spending more money than I have; B) having sex with people I hardly know; C) drinking too much; D) taking drugs; E) eating binges; F) reckless driving." Endorsed items were coded as 1 . The mean for this scale was 2.08 $(S D=1.83$; range: $0-6 ; \alpha=.74)$.

\section{Results and Discussion}

\section{Descriptive Statistics}

We first examined gender differences in narcissism, impulsivity-related traits, and SDB. There was no significant difference for the NPI or SDB. For the impulsivity-related traits, there were significant differences in 3 of the 10 variables (i.e., BIS, BAS Reward Responsiveness, UPPS-P Sensation Seeking) such that women had higher BIS scores and men had higher scores on the remaining two vari- 
ables. We tested the correlations between narcissism and the impulsivity-related traits and SDB separately by gender; there were two significant differences such that BAS-Reward responsiveness was significantly more strongly related $(z=2.03, p<.05)$ to SDB for men $(r=.37, p<.01)$ than women $(r=.09, n s)$. Alternatively, (Lack of) Premeditation was significantly more strongly related $(z=2.28$, $p \leq .05)$ to SDB for women $(r=.41, p<.01)$ than men $(r=.10, n s)$.

\section{Narcissism, Impulsivity, and SDB}

In Table 1, we report the bivariate correlations between the impulsivity-related traits and narcissism and the SDB composite. Narcissism was significantly negatively related to BIS and positively related to BAS-Drive and Fun Seeking and UPPS-P Sensation Seeking. It was negatively correlated with a lack of Perseverance (i.e., high NPI scores indicated more perseverance). Narcissism was uncorrelated with BAS-Reward Responsiveness, Negative and Positive Urgency, (Lack of) Premeditation, and the Brief Self-Control Scale. The mean effect size (reverse scoring the BIS and Brief Self-Control Scale) for the relations between narcissism and the impulsivity-related traits was .09. ${ }^{4}$ Narcissism also demonstrated a small but significant positive correlation with the self-defeating behaviors composite, $r=.17, p<.05$. The impulsivity-related traits were generally significantly related to the SDB composite, with a mean effect size of .30 .

Does Impulsivity Account for the Relation Between Narcissism and $S D B$ ?

In these analyses, we tested multiple models of why narcissism is related to SDB. In the first sets of analyses, we test whether the relations between narcissism and SDB are mediated by impulsivityrelated traits. We do this separately for (1) UPPS-P scales, (2) BIS/BAS scales, and (3) BSCS. In the second set of analyses, we tested whether other basic personality traits explain this link using domains from the FFM. Based on previous work (e.g., Miller \& Campbell, 2008; Paulhus \& Williams, 2002), we expected that narcissism would be related to SDB as a result of Agreeableness and/or

4. Individual correlations were transformed using the Fisher-Z transformation before being averaged and then transformed back before reporting the mean effect size. 


\section{Table 1}

Correlations Between Narcissism, Measures of Impulsivity, and Self-Defeating Behaviors

\begin{tabular}{lcc}
\hline & \multicolumn{2}{c}{ Self-Defeating } \\
& Narcissism & Behaviors \\
\hline Impulsivity-related traits & & \\
BIS/BAS & $-.30^{* *}$ & .06 \\
BIS & .14 & $.18^{*}$ \\
BAS-Reward Responsiveness & $.36^{* *}$ & $.18^{*}$ \\
BAS-Drive & $.20^{* * *}$ & $.41^{* * *}$ \\
BAS-Fun Seeking & -.06 & $.48^{* *}$ \\
UPPS-P & .05 & $.28^{* * *}$ \\
Negative Urgency & $-.26^{* * *}$ & $.27^{* * *}$ \\
Positive Urgency & -.02 & $.29^{* * *}$ \\
(Lack of) Perseverance & $.24^{* * *}$ & $.21^{* *}$ \\
(Lack of) Premeditation & .08 & $-.63^{* * *}$ \\
Sensation Seeking & .09 & .30 \\
Brief Self-Control Scale & & \\
M Effect Size (with BIS and SCS reverse & & \\
scored) & & \\
Self-defeating behaviors & & \\
Impulsive behaviors (e.g., spending too much, & .17 & \\
sex with strangers, drinking too much, taking & & \\
drugs, eating binges, reckless driving) & & \\
\hline
\end{tabular}

Notes: These findings come from Study 2. BIS: Behavioral Inhibition System; BAS: Behavioral Activation System; UPPS-P: UPPS-P Impulsive Behavior Scale. $* p<.05, * * p<.01$.

Extraversion. However, we also tested the role of Conscientiousness, as it is thought to be the FFM domain with the most impulsivityrelated traits (see Whiteside \& Lynam, 2001).

Do the UPPS-P Scales Account for the Narcissism-SDB relation?

We tested whether the five UPPS-P impulsivity dimensions mediated the link between narcissism and SDB (see Figure 1b). The total effect of narcissism on SDB was significant $(\mathrm{B}=.04, p<.05)$ and remained significant even when the mediators were included in the model $(\mathrm{B}=.05, p<.01)$. The total indirect effect of narcissism on SDB 
through the five mediating variables was not significant, with a point estimate of -.006 and a $95 \%$ BCA confidence interval of -.03 to .02. There was evidence of a significant unique mediating effect of UPPS-P Sensation Seeking; the point estimate for this dimension was .01 with a $95 \%$ BCA confidence interval of .001 to .025 .

Do the BIS/BAS Scales Account for the Narcissism-SDB Relation?

Next, we tested whether the BIS and BAS scales mediated the relation between narcissism and SDB (see Figure 2a). The total effect of narcissism on SDB was significant $(\mathrm{B}=.04, p<.05)$ and demonstrated a trend toward significance even when the mediators were included $(\mathrm{B}=.03, p<.07)$. The total indirect effect of narcissism on SDB through the BIS/BAS variables was not significant, with a point estimate of .007 and a $95 \%$ BCA confidence interval of -.02 to .03 . There was evidence of a significant unique mediating effect of BAS Fun Seeking; the point estimate for this dimension was .02 with a $95 \%$ BCA confidence interval of .004 to .04 .

Does the Brief Self-Control Scale Account for the Narcissism-SDB Relation?

Next, we tested whether the BSCS mediated the relation between narcissism and SDB (see Figure $2 \mathrm{~b}$ ). The total effect of narcissism on $\mathrm{SDB}$ was significant $(\mathrm{B}=.04, p<.05)$ and remained so once the mediator was included in the model $(\mathrm{B}=.05, p<.01)$. The total indirect effect of narcissism on SDB through the mediating variable was not significant, with a point estimate of -.012 and a $95 \%$ BCA confidence interval of -.04 to .01 .

Do Extraversion and Agreeableness Account for the Narcissism-SDB Relation?

The same analytic procedure was used here except that the mediators were Extraversion and Agreeableness (see Figure 3a). In this case, the total effect of narcissism on SDB $(\mathrm{B}=.04, p<.05)$ decreased when the mediators were included $(\mathrm{B}=-.02, n s)$. The total indirect effect of NPI scores on SDB through the two FFM dimensions was significant, with a point estimate of .06 and a $95 \%$ BCA confidence interval of .02 to .11 . An examination of the specific indirect effects 

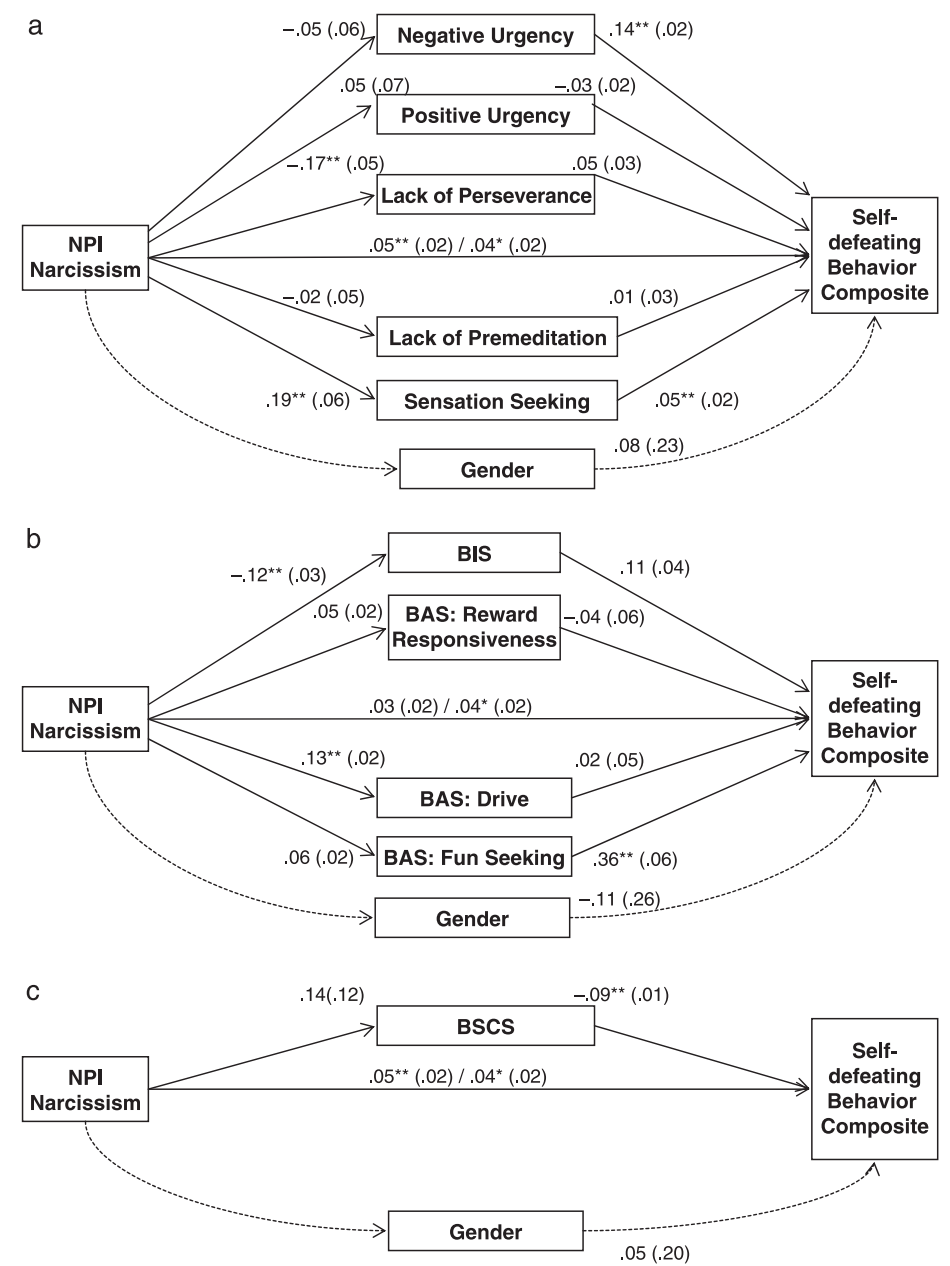

Figure 2

a: Test of a mediation model: NPI narcissism and self-defeating behaviors mediated through UPPS-P impulsivity dimensions controlling for gender. b: Test of a mediation model: NPI narcissism and self-defeating behavior mediated through BIS/BAS controlling for gender (Study 2). c: Test of a mediation model: NPI narcissism and self-defeating behavior mediated through BSCS controlling for gender (Study 2). Path values represent unstandardized regression coefficients. Standard errors are noted in parentheses. Values before the slash represent the direct effect of narcissism on the self-defeating behavior composite (SDBC) after the inclusion of the mediating variables. Values after the slash represent the effect on narcissism on IBC prior to the inclusion of the mediators. ${ }^{*} p<.05, * * p<.01$. 
revealed that both Agreeableness (point estimate $=.04 ; 95 \%$ BCA confidence interval $=.01-.06$ ) and Extraversion (point estimate $=.03 ; 95 \%$ BCA confidence interval $=.006-.05)$ were significant unique mediators of the relation between narcissism and SDB.

Do Extraversion, Agreeableness, and Conscientiousness Account for the Narcissism-SDB Relation?

Finally, the same model was run with the addition of Conscientiousness as a potential mediator along with Extraversion and Agreeableness (see Figure 3b). Again, the total effect of NPI scores on SDB $(\mathrm{B}=.04, p<.05)$ decreased when the three mediators were included $(\mathrm{B}=.00, n s)$. However, the total indirect effect of NPI scores on the outcome variable through the three FFM dimensions was not significant, with a point estimate of .04 and a $95 \%$ BCA confidence interval of -.0001 to .08 . As with the earlier analysis, both Extraversion and Agreeableness remained significant unique mediators; Conscientiousness was also a significant unique mediator, with a point estimate of -.03 and a $95 \%$ BCA confidence interval of -.06 to -.02 . However, this relation was not consistent with the narcissism-impulsivity hypothesis in that narcissism was positively related to Conscientiousness, not negatively related.

To summarize, in Study 2 we broadened our test of the narcissism-impulsivity hypothesis by examining the link between narcissism and several impulsivity-related traits and used a broader measure of SDB. In addition, we tested an alternative mediation model in which levels of Extraversion and Agreeableness were thought to explain the narcissism-SDB relation. The results suggest that narcissism is linked to Extraversion-related aspects of impulsivity that focus on sensation and reward seeking but is not linked to Conscientiousness-based impulsivity-traits or traits related to impulsive behaviors driven by emotional dysregulation. Mediation analyses show that sensation-seeking-type traits did partially mediate the narcissism-SDB behavior but did so to a lesser degree than a mediation model composed of Extraversion and Agreeableness.

\section{GENERAL DISCUSSION}

Our goal in the present research was to clarify the nature of the relations among narcissism, impulsivity, and self-defeating behaviors. 

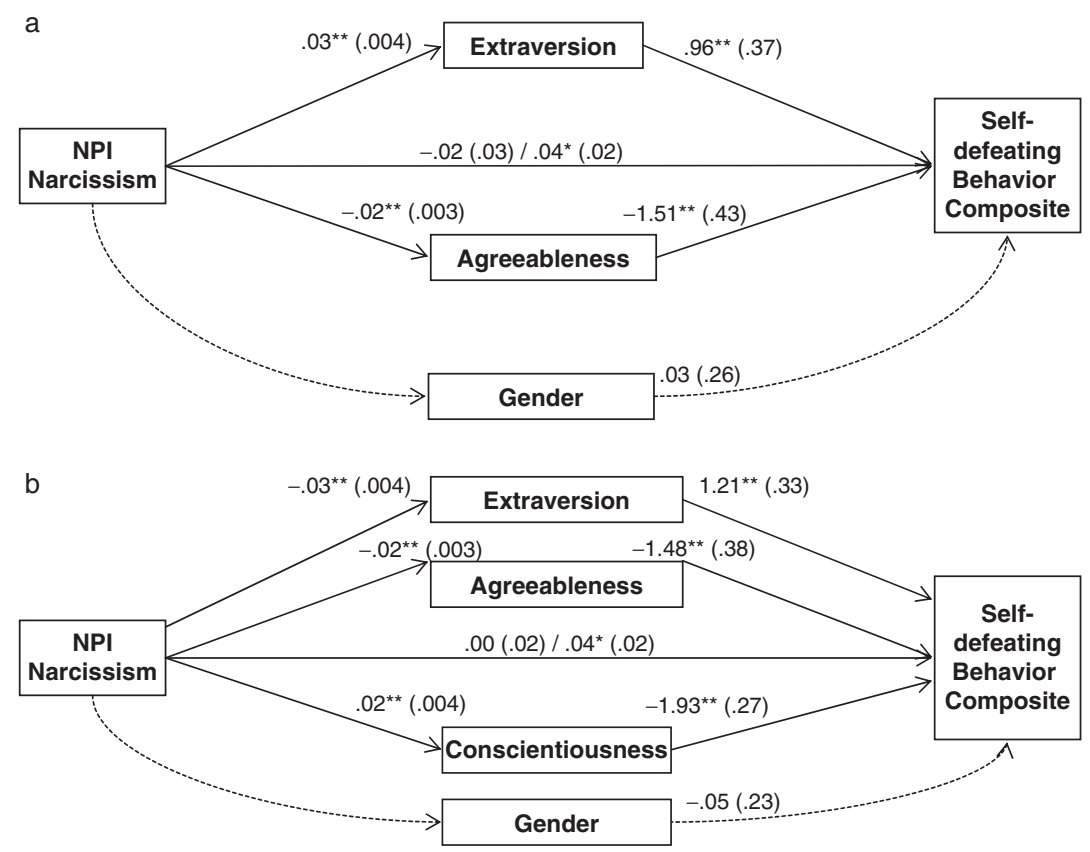

Figure 3

a: Test of a mediation model: NPI narcissism and self-defeating behavior mediated through Extraversion and Agreeableness controlling for gender (Study 2). b: Test of a mediation model: NPI narcissism and self-defeating behavior mediated through Extraversion, Agreeableness, and Conscientiousness controlling for gender (Study 2). Path values represent unstandardized regression coefficients. Standard errors are noted in parentheses. Values before the slash represent the direct effect of narcissism on the self-defeating behavior composite (SDBC) after the inclusion of the mediating variables. Values after the slash represent the effect on narcissism on IBC prior to the inclusion of the mediators. ${ }^{*} p<.05,{ }^{* *} p<.01$.

We heeded the suggestion that "studies examining narcissism should include multiple well-validated measures of impulsivity" (Vazire \& Funder, 2006, p. 162), specifically examining the links between narcissism and several models of impulsivity and reward sensitivity including the BIS/BAS (Carver \& White, 1994), the UPPS-P model (Lynam et al., 2006; Whiteside \& Lynam, 2001), a broad self-control scale (BSCS; Tangney et al., 2004), and an impulsiveness scale (BIS11; Patton et al., 1995). We also examined whether these various conceptualizations explained why narcissistic individuals engage in 
behaviors termed "self-defeating" by Vazire and Funder such as aggression. Finally, we put forth a meditational model based on an alternative trait model of narcissism in which narcissism is conceptualized primarily by high scores on Extraversion (particularly the agentic aspects of this dimension, such as assertiveness and excitement seeking) and low scores on Agreeableness. Several studies have suggested that, at the level of general personality traits, these domains may be thought of as core components of narcissism (e.g., Miller \& Campbell, 2008; Paulhus \& Williams, 2002).

Overall, trait narcissism, as assessed using the NPI, was neither universally nor strongly linked with impulsivity-related traits, as evidenced by a small mean effect sizes $(r=.13)$ in Study 1 and Study 2 $(r=.09)$. Instead, NPI narcissism appears to be linked with more specific traits, such as sensation seeking, an approach-oriented, "appetitive motivation" system (BAS; Carver \& White, 1994), and lower scores on an "aversive motivation" system (BIS; Carver \& White, 1994). The mean effect size for these types of traits in Study 2 $(r=.25$; e.g., sensation seeking, BIS/BAS) is closer to the effect size found by Vazire and Funder (2006), albeit smaller. This suggests that narcissistic individuals harbor a diminished sensitivity to signs of punishment or nonreward and an increased sensitivity to signs of reinforcement. These individuals are motivated toward approach behavior in situations that they deem rewarding (e.g., possibility for self-enhancement; increased status/dominance) and have weaker inhibition systems such that signs of punishment are weighted less heavily. The links between these reward-sensitivity traits and narcissism are consistent with past examinations of narcissism, sensation seeking (e.g., Emmons, 1981; Raskin \& Terry, 1988), and behavioral activation/inhibition (Foster \& Trimm, 2008). Because recent personality research suggests that dimensions such as BAS should be conceptualized as indicators of Extraversion rather than Conscientiousness (Smillie, Pickering, et al., 2006), a link between narcissism and Extraversion-based conceptualizations of impulsivity is congruent with findings that demonstrate that Extraversion is a core component of NPI narcissism (e.g., Miller \& Campbell, 2008; Paulhus \& Williams, 2002).

The nonsignificant relations found here between narcissism and Conscientiousness-based conceptualizations of impulsivity (e.g., [Lack of] Premeditation and Perseverance) are congruent with past research suggesting that this personality domain is not a significant 
component of narcissism (e.g., Paulhus \& Williams, 2002; Samuel \& Widiger, 2008). Across the two current samples, the mean effect size for impulsivity-related traits that appear to stem from the broader domain of Conscientiousness (i.e., Perseverance, Premeditation, BSCS, and the BIS-11 subscales) was $r=.00$. It does not appear that narcissistic individuals have difficulty weighing the cost and benefits of their actions in a deliberate, thoughtful manner. Instead, they are apt to pursue their goals (e.g., being seen as dominant) in an immediate and forceful manner that, at least to an observer, appears to ignore the costs of those behaviors.

In addition, impulsivity due to emotional dysregulation (i.e., Negative and Positive Urgency) was not correlated with narcissism (i.e., mean effect size, $r=-.01$ ). One would expect this, particularly for Negative Urgency, given that narcissism, as measured by the NPI, is not linked with psychological distress and negative affect (Miller \& Campbell, 2008; Rhodewalt, Madrian, \& Cheney, 1998). Although one might expect a correlation between narcissism and Positive Urgency, as it seems to reference positive affect (a known correlate of narcissism; Rhodewalt et al., 1998), Positive Urgency is actually most strongly correlated with Negative Urgency (Cyders et al., 2007; current study, $r=.61, p<.01)$ of the other UPPS-P domains and manifested a significant, positive correlation with Neuroticism in the current sample (i.e., $r=.24, p<.01$ ). This may explain the lack of correlation between narcissism and Positive Urgency.

The second part of the narcissism-impulsivity hypothesis suggests that impulsivity partially explains why narcissism is related to SDB. Although narcissism was related to aggression manifested in a laboratory setting (Study 1) and a composite measure of SDB (Study 2), the relation was not accounted for by any of the various models/assessments of impulsivity. Instead, we were able to demonstrate that other basic personality traits do account for this relation, namely, Extraversion and low Agreeableness (but not low Conscientiousness). It is important to note, however, that two impulsivityrelated scales did show a significant unique mediating effect, despite a nonsignificant total indirect effect for the larger model from which they are derived. Research has demonstrated that these two scales, BAS Fun Seeking and UPPS-P Sensation Seeking, are most strongly linked to Extraversion (Smillie, Jackson, et al., 2006; Smits \& Boeck, 2006; Whiteside \& Lynam, 2001). Alternatively, scales related to impulsivity driven by emotional dysregulation or a lack of fore- 
thought failed to account for a statistically significant portion of the narcissism-impulsivity relation in all analyses.

Thus, for NPI narcissism, there appear to be at least two forces that influence the likelihood of engaging in SDB - an approach orientation in which individuals are driven to pursue reward/excitement and an antagonistic interpersonal orientation. These findings are consistent with studies that suggest that Extraversion and Agreeableness are two of the major personality dimensions from comprehensive models of personality most strongly related to narcissism (e.g., Jakobwitz \& Egan, 2006; Miller \& Campbell, 2008; Paulhus \& Williams, 2002) and also that these dimensions are more likely to explain the relation between narcissism and SDB, particularly Agreeableness. As noted earlier, meta-analytic reviews and single studies have documented a significant and consistent negative relation between Agreeableness and antisocial behavior, risky sex, and substance use (e.g., Flory et al., 2002; Hoyle et al., 2000; Miller \& Lynam, 2001). Disagreeableness is also related with constructs that may explain why narcissistic individuals engage in these self-defeating behaviors such as higher levels of entitlement (Pryor, Miller \& Gaughan, 2008) and lower levels of forgiveness (Exline, Baumeister, Bushman, Campbell, $\&$ Finkel, 2004), empathy and willingness to help others (Graziano, Habashi, Sheese, \& Tobin, 2007), as well as a tendency to process social information in a hostile, biased manner that is likely to lead to aggressive responding (Miller, Lynam, \& Jones, 2008).

Given the substantial relation between Agreeableness and narcissism, we believe there are several potential pathways through which a narcissistic, antagonistic individual could engage in self-defeating behaviors. In addition, we believe that low Agreeableness is a better explanatory variable than impulsivity for a number of findings discussed by Vazire and Funder (2006), such as research linking narcissism with the likelihood to "endorse rape-supportive statements, enjoy watching a film depicting consensual affectionate activity followed by rape, and punish a female confederate for refusing to read aloud to them a sexually arousing passage" (Bushman, Bonacci, van Dijk, \& Baumeister, 2003). It seems less plausible that these experimental outcomes (e.g., support of rape; enjoyment of rape-related film scenes) are the result of participants' impulsivity rather than the callousness and egocentricity that is part of dispositional Disagreeableness or the need for status and dominance that is part of Extraversion. 
Our results also confirm previous research that both narcissism (e.g., Bushman \& Baumeister, 1998) and impulsivity (Miller \& Lynam, 2001; Whiteside et al., 2005) are predictors of aggressive, risky behavior. However, it appears that these constructs-impulsivity and narcissism - are relatively independent of each other (with the exception of the sensation-seeking-like constructs) and demonstrate significant, unique effects on these outcomes.

\section{Limitations and Future Research}

There are several limitations to our research. First, we primarily relied on self-reported measures for most of our constructs, with the exception of a laboratory measure of physical aggression in Study 1. It is possible that a stronger role for impulsivity would be manifested if reports of others were used, although Miller and Campbell (2008) found that informant reports of Conscientiousness were unrelated to self-reported NPI scores $(r=-.05)$. Further work is needed using other assessment methodologies, including informant reports and behavioral assessments. Second, given the cross-sectional nature of the current study, longitudinal examinations of narcissism and SDB that include behavioral measures of impulsivity would be a valuable addition to the literature. Third, both studies used undergraduate samples, which may limit the generalizability of our findings, although undergraduates made up a large proportion of the combined sample used in the original meta-analysis, suggesting that our current samples can serve as a reasonable comparison groups. Fourth, the current data were based on general behavior patterns; it is possible that problems of impulse control might be evident only under certain conditions, such as ego threat. Fifth, we did not include among our dependent variables one of the outcomes posited to be related to narcissism and impulsivity by Vazire and Funder - selfenhancement. This aspect of their model still needs to be tested.

\section{Conclusions}

Our goal in the present research was to test the narcissism-impulsivity hypothesis against an alternative hypothesis that the effect of narcissism on SDBs is due to the roles of Agreeableness and Extraversion. It is clear that the relation between narcissism and impulsivity is complex and depends on how broadly "impulsivity" is conceptualized. If impulsivity is conceptualized primarily as sensa- 
tion seeking and behavioral activation, then a significant relation with narcissism can be expected; if impulsivity is defined more narrowly to represent traits related to Conscientiousness or emotional dysregulation, the relation would appear to be weak or nonexistent. The current results suggest that a reformulation of the narcissismimpulsivity hypothesis to focus on the role of Extraversion-based traits like sensation seeking would have more empirical support. In addition, it is important to acknowledge that narcissism is strongly linked to an array of antagonistic interpersonal qualities, which appear to play an important role in explaining why narcissistic individuals engage in these types of problematic behaviors. Models that attempt to explain the self-defeating behaviors of these individuals will have greater predictive power to the extent that they include both of these personality pathways.

\section{REFERENCES}

Anestis, M. D., Selby, E. A., \& Joiner, T. E. (2007). The role of urgency in maladaptive behaviors. Behaviour Research and Therapy, 45, 3018-3029.

Bettencourt, B. A., Talley, A., Benjamin, A. J., \& Valentine, J. (2006). Personality and aggressive behavior under provoking and neutral conditions: A meta-analytic review. Psychological Bulletin, 132, 751-777.

Block, J. H., \& Block, J. (1980). The role of ego-control and resiliency in the organization of behavior. In W. A. Collins (Ed.), Development of cognition, affect, and social relations: The Minnesota symposia on child psychology (Vol. 13). Hillsdale, NJ: Erlbaum.

Block, J., \& Kremen, A. M. (1996). IQ and ego-resiliency: Conceptual and empirical connections and separateness. Journal of Personality and Social Psychology, 70, 349-361.

Bushman, B. J., \& Baumeister, R. F. (1998). Threatened egotism, narcissism, selfesteem, and direct and displaced aggression: Does self-love or self-hate lead to violence? Journal of Personality and Social Psychology, 75, 219-229.

Bushman, B. J., Bonacci, A. M., van Dijk, M., \& Baumeister, R. F. (2003). Narcissism, sexual refusal, and aggression: Testing a narcissistic reaction model of sexual coercion. Journal of Personality and Social Psychology, 84, $1027-1040$.

Campbell, W. K. (1999). Narcissism and romantic attraction. Journal of Personality and Social Psychology, 77, 1254-1270.

Campbell, W. K., Brunell, A. B., \& Finkel, E. J. (2006). Narcissism, interpersonal self-regulation, and romantic relationships: An agency model approach. In K. Vohs \& E. Finkel (Eds.), Self and Relationships: Connecting intrapersonal and interpersonal processes (pp. 57-83). New York: Guilford Press. 
Campbell, W. K., Bush, C. P., Brunell, A. B., \& Shelton, J. (2005). Understanding the social costs of narcissism: The case of tragedy of the commons. Personality and Social Psychology Bulletin, 31, 1358-1368.

Carroll, L. (1987). A study of narcissism, affiliation, intimacy, and power motives among students in business administration. Psychological Reports, 61, 355358.

Carver, C. S., \& White, T. L. (1994). Behavioral inhibition, behavioral activation, and affective responses to impending reward and punishment: The BIS/BAS scales. Journal of Personality and Social Psychology, 67, 319-333.

Cohen, J., Cohen, P., West, S. G., \& Aiken, L. S. (2003). Applied multiple regression/correlation analysis for behavioral sciences (3rd ed.). Mahwah, NJ: Erlbaum.

Costa, P. T., \& McCrae, R. R. (1992). Revised NEO Personality Inventory (NEO$P I-R$ ) and NEO Five-Factor Inventory (NEO-FFI) Professional Manual. Odessa, FL: Psychological Assessment Resources.

Cyders, M. A., Smith, G. T., Spillane, N. S., Fischer, S., \& Annus, A. M. (2007). Integration of impulsivity and positive mood to predict risky behavior: Development and validation of a measure of positive urgency. Psychological Assessment, 19, 107-118.

Depue, R. A., \& Collins, P. F. (1999). Neurobiology of the structures of personality: Dopamine, facilitation of incentive motivation, and extraversion. Behavioral and Brain Sciences, 22, 491-569.

Emmons, R. A. (1981). Relationship between narcissism and sensation seeking. Psychological Reports, 48, 247-250.

Exline, J. J., Baumeister, R. F., Bushman, B. J., Campbell, W. K., \& Finkel, E. J. (2004). Too proud to let go: Narcissistic entitlement as a barrier to forgiveness. Journal of Personality and Social Psychology, 87, 894-912.

Flory, K., Lynam, D., Milich, R., Leukefeld, C., \& Clayton, R. (2002). The relations among personality, symptoms of alcohol and marijuana abuse, and symptoms of comorbid psychopathology: Results from a community sample. Experimental and Clinical Psychopharmacology, 10, 425-434.

Foster, J. D., \& Trimm, R. F. (2008). On being eager and uninhibited: Narcissism and approach-avoidance motivation. Personality and Social Psychology Bulletin, 34, 1004-1017.

Funder, D. C., \& Block, J. (1989). The role of ego-control, ego-resiliency, and IQ in delay of gratification in adolescence. Journal of Personality and Social Psychology, 57, 1041-1050.

Gough, H. G. (1969). Manual for the California Psychological Inventory. Palo Alto, CA: Consulting Psychology Press.

Gray, J. A. (1972). The psychophysiological basis of Introversion-Extraversion. A modification of Eysenck's theory. In V. D. Nebylitsyn \& J. A. Gray (Eds.), The biological bases of individual behaviour (pp. 182-205). San Diego, CA: Academic Press.

Graziano, W. G., \& Eisenberg, N. (1997). Agreeableness: A dimension of personality. In R. Hogan, J. Johnson., \& S. Briggs (Eds.), Handbook of personality psychology (pp. 795-824). San Diego, CA: Academic Press. 
Graziano, W. G., Habashi, M. M., Sheese, B. E., \& Tobin, R. M. (2007). Agreeableness, empathy, and helping: A person x situation perspective. Journal of Personality and Social Psychology, 93, 583-599.

Hyler, S. E. (1994). Personality Diagnostic Questionnaire-4. Unpublished test, New York State Psychiatric Institute.

Hoyle, R. H., Fejfar, M. C., \& Miller, J. D. (2000). Personality and sexual risk taking: A quantitative review. Journal of Personality, 68, 1203-1231.

Jakobwitz, S., \& Egan, V. (2006). The dark triad and normal personality traits. Personality and Individual Differences, 40, 331-339.

Johnson, S. L., Turner, R. J., \& Iwata, N. (2003). BIS/BAS levels and psychiatric disorder: An epidemiological study. Journal of Psychopathology and Behavioral Assessment, 25, 25-36.

Konrath, S., Bushman, B. J., \& Campbell, W. K. (2006). Attenuating the link between threatened egotism and aggression. Psychological Science, 17, 9951001.

Krueger, R. F., Markon, K. E., Patrick, C. J., Benning, S. D., \& Kramer, M. D. (2007). Linking antisocial behavior, substance use, and personality: An integrative quantitative model of the adult externalizing spectrum. Journal of $A b$ normal Psychology, 116, 645-666.

Lakey, C. E., Rose, P., Campbell, W. K., \& Goodie, A. S. (2008). Probing the link between narcissism and gambling: The mediating role of decision-making biases. Journal of Behavioral Decision Making, 21, 113-137.

LaRowe, S. D., Patrick, C. J., Curtin, J. J., \& Kline, J. P. (2006). Personality correlates of startle habituation. Biological Psychology, 72, 257-264.

Letzring, T. D., Block, J., \& Funder, D. C. (2005). Ego-control and ego-resiliency: Generalization of self-report scales based on personality descriptions from acquaintances, clinicians, and the self. Journal of Research in Personality, 39, $395-422$.

Loxton, N. J., \& Dawe, S. (2001). Alcohol abuse and dysfunctional eating in adolescent girls: The influence of individual differences in sensitivity to reward and punishment. International Journal of Eating Disorders, 29, 455-462.

Lynam, D. R., Smith, G. T., Whiteside, S. P., \& Cyders, M. A. (2006). The UPPS$P$ : Assessing five personality pathways to impulsive behavior. Technical Report. West Lafayette, IN: Purdue University.

Manuck, S. B., Flory, J. D., McCaffery, J. M., Matthews, K. A., Mann, J. J., \& Muldoon, M. F. (1998). Aggression, impulsivity, and central nervous system serotonergic responsivity in a non-patient sample. Neuropsychopharmacology, 19, 287-299.

Miller, J. D., \& Campbell, W.K (2008). Comparing clinical and social-personality conceptualizations of narcissism. Journal of Personality, 76, 449-476.

Miller, J. D., \& Lynam, D. R. (2001). Structural models of personality and their relation to antisocial behavior: A meta-analysis. Criminology, 39, 765-798.

Miller, J. D., Lynam, D. R., \& Jones, S. (2008). Externalizing behaviors through the lens of the Five-Factor Model: A focus on agreeableness and conscientiousness. Journal of Personality Assessment, 90, 158-164.

Morf, C. C., \& Rhodewalt, F. (2001). Unraveling the paradoxes of narcissism: A dynamic self-regulatory processing model. Psychological Inquiry, 12, 177-196. 
Muraven, M. R., \& Baumeister, R. F. (2000). Self-regulation and depletion of limited resources: Does self-control resemble a muscle? Psychological Bulletin, 126, 247-259.

Patton, J. H., Stanford, M. S., \& Barratt, E. S. (1995). Factor structure of the Barratt Impulsiveness Scale. Journal of Clinical Psychology, 51, $768-774$.

Paulhus, D. L. (2001). Normal narcissism: Two minimalist accounts. Psychological Inquiry, 12, 228-300.

Paulhus, D. L., \& Williams, K. M. (2002). The dark triad of personality: Narcissism, Machiavellianism, and psychopathy. Journal of Research in Personality, 36, 556-563.

Preacher, K. J., \& Hayes, A. F. (2004). SPSS and SAS procedures for estimating indirect effects in simple mediation models. Behavior Research Methods, Instruments, and Computers, 36, 717-731.

Preacher, K. J., \& Hayes, A. F. (2006). Asymptotic and resampling strategies for assessing and comparing indirect effects in simple and multiple mediator models. Manuscript submitted for publication.

Pryor, L. R., Miller, J. D., \& Gaughan, E. T. (2008). A comparison of the Psychological Entitlement Scale and the Narcissistic Personality Inventory's Entitlement scale: Relations with general personality traits and personality disorders. Journal of Personality Assessment, 90, 517-520.

Quilty, L. C., \& Oakman, J. M. (2004). The assessment of behavioural activation-The relationship between impulsivity and behavioural activation. Personality and Individual Differences, 37, 429-442.

Raskin, R. N., Novacek, J., \& Hogan, R. (1991). Narcissistic self-esteem management. Journal of Personality and Social Psychology, 60, 911-918.

Raskin, R., \& Terry, H. (1988). A principle-components analysis of the Narcissistic Personality Inventory and further evidence of its construct validity. Journal of Personality and Social Psychology, 54, 890-902.

Reidy, D. E., Zeichner, A., Foster, J. D., \& Martinez, M. A. (2008). Effects of narcissistic entitlement and exploitativeness on human physical aggression. Personality and Individual Differences, 44, 865-875.

Rhodewalt, F., Madrian, J. C., \& Cheney, S. (1998). Narcissism, self-knowledge organization, and emotional reactivity: The effect of daily experiences on selfesteem and affect. Personality and Social Psychology Bulletin, 24, 75-87.

Samuel, D. B., \& Widiger, T. A. (2008). Convergence of narcissism measures from the perspective of general personality functioning. Assessment, 15, 364-374.

Saulsman, L. M., \& Page, A. C. (2004). The five-factor model and personality disorder empirical literature: A meta-analytic review. Clinical Psychology Review, 23, 1055-1085.

Smillie, L. D., Jackson, C. J., \& Dalgleish, L. I. (2006). Conceptual distinctions among Carver and White's (1994) BAS scales: A reward-reactivity versus trait impulsivity perspective. Personality and Individual Differences, 40, 1039-1050.

Smillie, L. D., Pickering, A. D., \& Jackson, C. J. (2006). The new reinforcement sensitivity theory: Implications for personality measurement. Personality and Social Psychology Review, 10, 320-335. 
Smits, D. J. M., \& Boeck, P. D. (2006). From BIS/BAS to the Big Five. European Journal of Personality, 20, 255-270.

Tangney, J. P., Baumeister, R. F., \& Boone, A. L. (2004). High self-control predicts good adjustment, less pathology, better grades, and interpersonal success. Journal of Personality, 72, 271-324.

Tellegen, A. (1985). Structures of mood and personality and their relevance to assessing anxiety, with an emphasis on self-report. In A. H. Tuma \& J. D. Maser (Eds.), Anxiety and the anxiety disorders (pp. 681-706). Hillsdale, NJ: Erlbaum.

Vazire, S., \& Funder, D. C. (2006). Impulsivity and the self-defeating behavior of narcissists. Personality and Social Psychology Review, 10, 154-165.

Wacker, J., Chavanon, M.-L., \& Stemmler, G. (2006). Investigating the dopaminergic basis of extraversion in humans: A multilevel approach. Journal of Personality and Social Psychology, 91, 171-187.

Whiteside, S. P., \& Lynam, D. R. (2001). The Five Factor Model and impulsivity: Using a structural model of personality to understand impulsivity. Personality and Individual Differences, 30, 669-689.

Whiteside, S. P., Lynam, D. R., Miller, J. D., \& Reynolds, S. K. (2005). Validation of the UPPS impulsive behavior scale: A four-factor model of impulsivity. European Journal of Personality, 19, 559-574.

Wiggins, J. S., \& Pincus, A.L (2002). Personality structure and the structure of personality disorders. In P. Costa Jr. \& T. Widiger (Eds.), Personality disorders and the five-factor model of personality (pp. 103-124). Washington, DC: American Psychological Association.

Zeichner, A., Frey, F. C., Parrott, D. J., \& Butryn, M. F. (1999). Measurement of laboratory aggression: A new response-choice paradigm. Psychology Reports, 85, 1229-1237.

Zeichner, A., Parrott, D. J., \& Frey, F. C. (2003). Gender differences in laboratory aggression under response choice conditions. Aggressive Behavior, 29, 95-106. 


\section{4}

